\title{
A new rating system for hydrogeological risk management along railway infrastructures in Prealpine zone (northern Italy)
}

\author{
P. Gattinoni ${ }^{1}$ (D) L. Scesi ${ }^{1} \cdot$ L. Arieni ${ }^{2} \cdot$ M. Canavesi ${ }^{2} \cdot$ F. Zaffaroni $^{3}$
}

Received: 13 November 2020 / Accepted: 13 February 2021 / Published online: 28 March 2021

(c) The Author(s) 2021

\begin{abstract}
Railway infrastructures in mountain areas often develop along hillslopes affected by geomorphological and hydrogeological processes which might lead hazardous events. Therefore, specific tools for risk analysis and management are required. This paper develops a new rating system (Railway Hydrogeological Management System, RHMS), based on a heuristic method which considers the susceptibility to different types of slope instabilities, as well as the peculiar features affecting the railway vulnerability. The proposed method introduces an iterative approach for the risk assessment, based on the definition of acceptability thresholds for the residual risk. The application of this method to a test area pointed out its feasibility, as well as its operational capability to identify the critical sections of the infrastructure, in which protection or mitigation measures are needed in order to reduce the risk.
\end{abstract}

Keywords Heuristic approach $\cdot$ Hydrogeological hazard $\cdot$ Intervention priority $\cdot$ Railway infrastructure $\cdot$ Risk assessment

\section{Introduction}

At present days, effective maintenance procedures for transport linear infrastructures (i.e. highways and railways) have to be optimised in order to provide high levels of safety, with peculiar concern over the economic issues [1]. More specifically, the transport infrastructures belonging to mountain areas are often affected by hydrogeological hazards, arising from geomorphological processes, such as slope instabilities or river dynamics. These events can pose a serious danger for travellers, but they can also involve significant maintenance costs, as well as service and operation interruptions. Therefore, proper methods for hydrogeological risk analysis and management have to be defined in order to identify the critical situations and then to plan protection and mitigation measures.

A quantitative analysis for the geological and hydrogeological risk assessment [2] should be based on the statistical

P. Gattinoni

paola.gattinoni@polimi.it

1 Department of Civil and Environmental Engineering, Politecnico Di Milano, Milan, Italy

2 ABMGEO S.R.L, Morazzone, Italy

3 FerrovieNord S.p.a, Milan, Italy assessment of both the geological hazard and the vulnerability of the infrastructure. Moreover, the economic value of the elements at risk should be considered.

Although quantitative risk analysis has become quite common in landslide risk management, for linear infrastructures these methods show some disadvantages, mainly connected to the lack of data, as well as to the high level of uncertainty usually affecting the available information [3]. Actually, linear infrastructures often cross environments which are very heterogeneous from a geological and geomorphological point of view, therefore involving different kinds of hazardous events, spanning from rock falls to soil slips, from floods to bank erosion. A quantitative hazard assessment for these events should be carried out at very large scale by using specific statistical tools [4]. This kind of quantitative assessment is quite time and data consuming; therefore, it is essential a prior identification of those sections in which the potential risk is higher than an acceptability threshold. The present technical note deals with this preliminary phase of qualitative risk analysis, and it is aimed at defining a rating method for identifying a relative scale of the hydrogeological risk along railways.

Over the last decades, many risk assessment systems have been proposed in order to identify hazardous slopes along highways and then prioritise the proper mitigation measures $([5,6]$ and references therein). One of the most 
well known of these systems is the Rockfall Hazard Rating System (RHRS, [7]), which is a qualitative risk assessment system for rock fall risk management. The main advantage of this method is its ability to join both the geological and infrastructure features within a standard ranking system, in which the knowledge from different experts is exploited [8]. Unfortunately, at present no method has been proposed for considering all types of landslide which can affect linear infrastructure corridors, neither specific methods for hydrogeological risk management along railways. One of the very few examples refers to hazard assessment of rainfall-induced landslides [9].

Moreover, when dealing with railway infrastructures the vulnerability assessment should take into account for the transit frequency and the response time of the system to dangerous events, which on its turn depends on the infrastructure features, as well as on the train type and load. This latter should also take into account for the crowding conditions, that is a time dependant (daily, weekly and seasonally) parameter quite difficult to evaluate. Finally, the infrastructure management needs the definition of risk acceptability thresholds, which is often one of the most critical elements in the risk analysis. In the present study a first attempt was made in order to introduce these elements in the hydrogeological risk analysis along railways. Actually, this study develops a heuristic method for the hydrogeological risk management along railways in mountain areas; the proposed method takes into account for different kinds of geological and hydrogeological hazards and for the vulnerability of the infrastructure, with the definition of specific parameters describing the railway risk exposure. The method was applied to a $20 \mathrm{~km}$ long infrastructure belonging to FerrovieNord S.p.a., located in the Prealpine area of northern Italy.

\section{Methods and materials}

\section{Methodological approach}

The proposed approach is named Railway Hydrogeological Management System (RHMS) and it is a risk rating system aimed at providing a comparison of the hydrogeological risk conditions among different sections along a railway infrastructure, in order to facilitate a prioritisation of the follow-up actions. The method modifies the existing method RHRS for highways [6] in order to introduce different kinds of hydrogeological hazards, as well as to adapt the method to the typical characteristics of the railway infrastructures.

RHMS develops through the following main steps:

1. Creation of a database with technical, geological, hydrogeological and morphological data;

2. Assessment of the hydrogeological susceptibility (S), with the identification of 5 classes of potential hazard (from very low to very high);

3. Assessment of the infrastructure vulnerability (V), with the identification of 5 classes (from very low to very high);

4. Risk and residual risk assessment and management.

In order to apply this method, a georeferenced database is needed, containing all geological, morphological, hydrogeological and technical data of each section of the infrastructure. Table 1 summarises all the parameters useful for the assessment of both the hydrogeological susceptibility and the infrastructure vulnerability.

The assessment of the hydrogeological susceptibility takes into account for geological, geomorphological and
Table 1 Parameters for the susceptibility (from $\mathrm{x}_{1}$ to $\mathrm{x}_{7}$ ) and vulnerability (from $\mathrm{x}_{8}$ to $\mathrm{x}_{10}$ ) with the corresponding normalised indexes

\begin{tabular}{|c|c|c|}
\hline \multicolumn{2}{|l|}{ Parameter } & \multirow{2}{*}{$\begin{array}{l}\text { Normalised index } \\
x_{1}=\frac{\mathrm{MP}^{-\mathrm{MP}_{\min }}}{\mathrm{MP}-\mathrm{MP}} \log _{3} 100\end{array}$} \\
\hline Mapped hazards & MH (Table 2a) & \\
\hline Previous instabilities & PI (Table 2b) & $x_{2}=\frac{\mathrm{PI}_{\max }-\mathrm{PI}_{\min }}{\mathrm{PI}_{\max }-\mathrm{PI}_{\min }} \log _{3} 100$ \\
\hline \multirow[t]{2}{*}{ Geological conditions } & RMR [10] for rock masses & $x_{3}=\frac{\mathrm{RMR}_{\max }-\mathrm{RMR}}{\mathrm{RMR}_{\max }-\mathrm{RMR}_{\min }} \log _{3} 100$ \\
\hline & $\mathrm{SC}$ (Table $2 \mathrm{c}$ ) for soils & $x_{3}=\frac{\mathrm{CG}_{\max }-\mathrm{CG}}{\mathrm{CG}_{\max }-\mathrm{CG}_{\min }} \log _{3} 100$ \\
\hline Slope height & $\mathrm{SH}(\mathrm{m})$ & $x_{4}=\frac{\mathrm{SH}^{-\mathrm{SH}_{\min }}}{\mathrm{SH}_{\max }-\mathrm{SH}_{\min }} \log _{3} 100$ \\
\hline Slope angle & $\mathrm{SA}\left({ }^{\circ}\right)$ & $x_{5}=\frac{\mathrm{SA}-\mathrm{SA}_{\min }}{\mathrm{SA}_{\max }-\mathrm{SA}_{\min }} \log _{3} 100$ \\
\hline Water & W (Table 2d) & $x_{6}=\frac{\mathrm{W}-\mathrm{W}_{\min }}{\mathrm{W}_{\max }-\mathrm{W}_{\min }} \log _{3} 100$ \\
\hline Vegetation cover & VC (Table 2e) & $x_{7}=\frac{\mathrm{VC}-\mathrm{VC}_{\min }}{\mathrm{VC}_{\max }-\mathrm{VC}_{\min }} \log _{3} 100$ \\
\hline Transit frequency & $\mathrm{TF}=\frac{\text { no. trains } / \mathrm{h}}{\text { speed }_{\left[\frac{\mathrm{km}}{\mathrm{h}}\right]}}$ lenght $_{[\mathrm{km}]}$ & $x_{8}=\frac{\mathrm{TF}-\mathrm{TF}_{\min }}{\mathrm{TF}_{\max }-\mathrm{TF}_{\min }} \log _{3} 100$ \\
\hline Distance from signals & $\mathrm{DS}(\mathrm{km})$ & $x_{9}=\frac{\mathrm{DS}_{\max }-\mathrm{DS}}{\mathrm{DS}_{\max }-\mathrm{DS}_{\min }} \log _{3} 100$ \\
\hline Slope distance & $\mathrm{SD}(\mathrm{m})$ & $x_{10}=\frac{\mathrm{SD}_{\max }-\mathrm{SD}}{\mathrm{SD}_{\max }-\mathrm{SD}_{\min }} \log _{3} 100$ \\
\hline
\end{tabular}


hydrogeological parameters, as well as for the presence of previous instabilities or mapped hazards. Actually, the first three parameters in Table 1 mainly have a geological relevance:

- Mapped hazard (MH) accounts for the geological and hydraulic processes (landslides, active fans, river erosion, flooding, etc.) identified and mapped by previous studies in a buffer $500 \mathrm{~m}$ wide around the railway axis (Table 2a);

Table 2 Classes of values for the qualitative parameters listed in Table 1: (a) mapped hazards (based on previous studies); (b) previous instability (PI) (based on on-site surveys); (c) size classification
- Previous instability (PI) refers to hazard events (such as rock falls and embankment failures) already occurred in the past, which may have directly affected the railway infrastructure (Table 2b);

- geological condition is a parameter depending on the geomaterial characterising the ground on which the railway develops; if the ground is constituted by rock masses, the index is based on the Rock Mass Rating (RMR) by Bieniawski [10]; indeed, the international literature provides other more complete classification systems, such as

(SC) for soils (based on American Standard for Testing and Materials ASTM [11]); (d) water (W) (based on on-site surveys); (e) vegetation cover (VC) (based on on-site surveys)

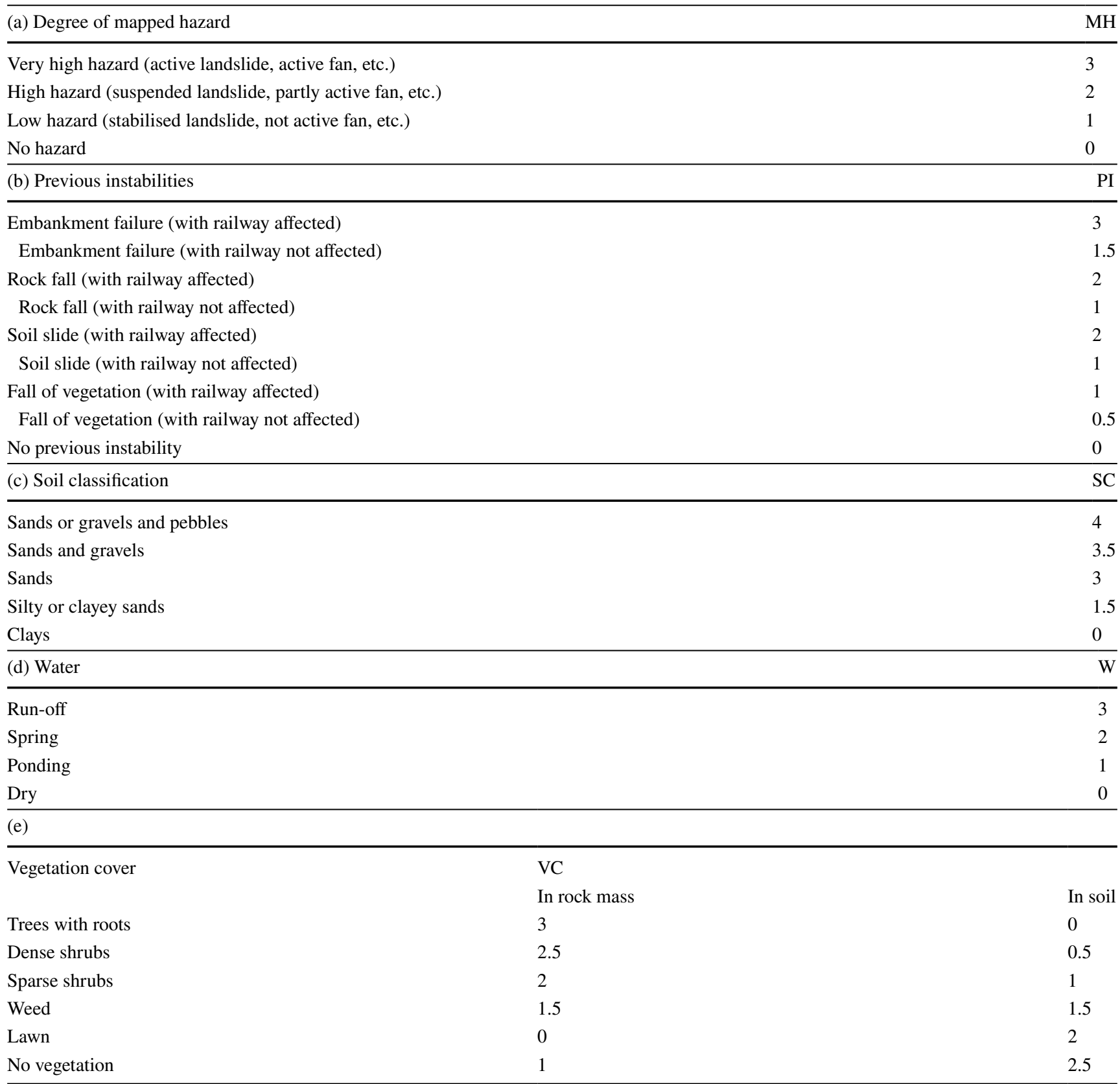


the Romana system [11], widespread used for landslide hazard assessment in rock masses [12]; yet, in the present study the simplest Bieniawski method was used in order to make the period for the on-site surveys compatible with the operational needs of the infrastructure; if the ground is composed by soil deposits, the index is based on the traditional grain size classification (SC) adopted by the American Standard for Testing and Materials [13] (Table 2c).

The two following parameters in Table 1 describe the geometrical and morphological conditions of the slope, specifically its height $(\mathrm{SH})$ and its angle ( $\mathrm{SA}$ ); the values of these parameters correspond to those actually measured during the on-site surveys.

The last two indexes are relevant for the hydrogeological susceptibility to landslide; they are:

- the presence of water $(\mathrm{W})$ : it is detected and classified during the on-site surveys, by attributing a higher (unfavourable) value to those phenomena that involve water flowing and therefore possible erosion, which can trigger slope instabilities [14, 15] (Table 2d);

- the vegetation cover (VC): for this parameter it is necessary to distinguish its effects on rock masses from those on soil deposits (Table 2e); actually, in rock masses the growth of vegetation having a significant root system can bring about a widening of joints, unfavourable for the slope stability [16]; on the contrary, in soils the root system of plants can provide a cohesive effect, involving stabilising effects [17].

These seven parameters mainly refer to the geological and hydrogeological conditions of the area and they contribute to the assessment of the landslide hydrogeological susceptibility. The following three parameters listed in Table 1 are representative of some technical characteristics of the infrastructure, and they contribute in defining its vulnerability.

At this aim, the first index is the Transit Frequency (TF), that is a function of the number of trains and their speed; this parameter is borrowed from the Average Vehicle Risk used for assessing risk along roads [18], and it is representative for the probability that a train is passing through a section of the infrastructure at the time the dangerous event occurs.

Moreover, the distance from signals (DS) was considered as a parameter representative of the possibility of reporting a problem along the infrastructure: the greater the distance of a section from the signal that precedes it in the travel direction, the less the vulnerability of the infrastructure will be, both because there is sufficient space for stopping and because there is time to activate the signal system. Of course this possibility depends on the presence of a monitoring and alert system, which can report in real time the presence of a problem along the route.

Finally, an index related to the railway ballast width was introduced; the Slope Distance (SD) is equal to the distance of the railway tracks from the adjacent slope edge, distinguishing the left and right side up to a maximum value of $15 \mathrm{~m}$. Obviously, the greater the distance, the lower the vulnerability of the infrastructure to a hazard event.

As many of these parameters are qualitative, they have been divided into classes and a ranking has been assigned to each class based on its willingness to risk (Table 2). Actually, all these elements (even the qualitative ones) have to be quantified with a standard ranking system and afterwards summed up in order to obtain the risk index.

At this aim, all the parameters are normalised in between their maximum and minimum value (according to the equations in Table 1). Afterwards, to each normalised index $x_{i}$ a ranking is assigned (in between 0 and 100) based on the following exponential equation:

$y_{i}=x_{i}^{3}$

Finally, the landslide hydrogeological susceptibility S (max value equal to 700 ) and the railway vulnerability $\mathrm{V}$ (max value equal to 300) are assessed through the two following equations:

$S_{r, l}=\sum_{1}^{7} y\left(x_{i}\right)$

$V_{r, l}=\sum_{8}^{10} y\left(x_{i}\right)$

where $x_{i}$ are the normalised indexes defined in Table 1 and $y\left(x_{i}\right)$ are their rankings; the subscripts $\mathrm{r}$ and 1 identify the track of the railway based on the transit direction.

As a result, five classes of susceptibility and vulnerability are identified, based on which the risk ranking $(\mathrm{R})$ can be assess, too. At this aim a matrix approach widespread used in heuristic methods for risk assessment was used [19] (Fig. 1).

By comparing the risk values in the different sections of the infrastructure, the critical situations can be identified in a relative scale. Actually, the risk ranking provides a relative evaluation which allows the identification along the route of those sections that are more critical than others. Within this relative scale, the manager of the infrastructure should define proper acceptability thresholds, based on economic and social issues. If the risk index exceeds the acceptability threshold $\left(a_{T}\right)$, protection or mitigation measures are needed as soon as possible in order to reduce the risk.

Moreover, a target threshold $\left(o_{T}\right)$ can be introduced as the goal to reach with long period planning (Fig. 2). 


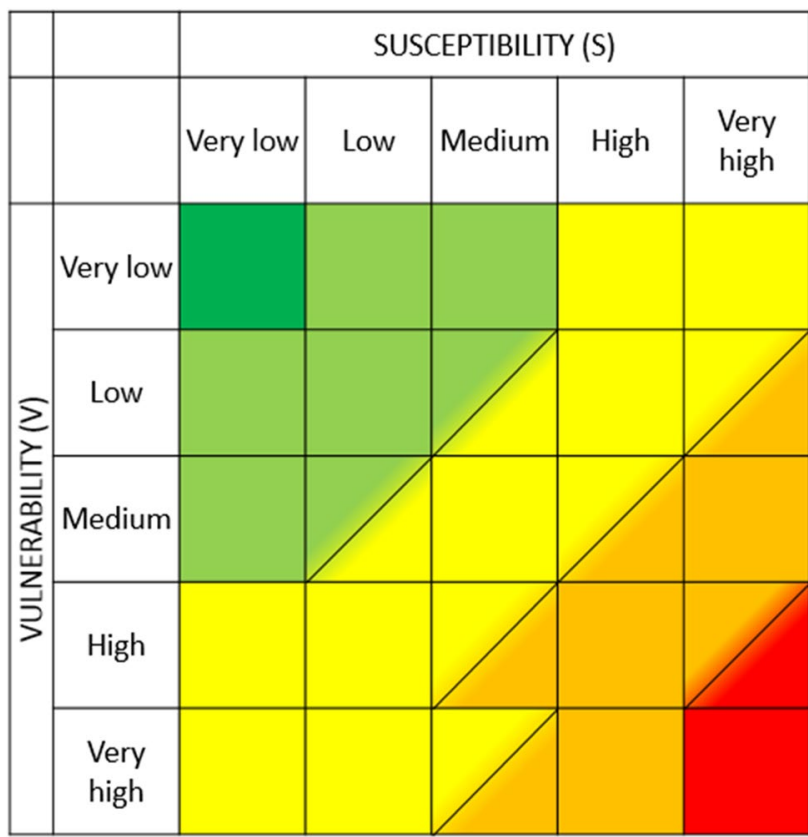

Fig. 1 Matrix for risk assessment [19]: red colour corresponds to very high risk, whereas black green corresponds to very low risk

In order to introduce in the risk assessment tool the presence of protection and mitigation measures, the risk rating $R$ can be corrected by multiplying it by a coefficient $(\rho)$ which takes into account for the presence, effectiveness and maintenance of protection (i.e. consolidation or draining systems) or mitigation (i.e. monitoring systems) measures (Table 3). In this way, a residual risk $R_{r}$ can be pointed out.

The acceptability and target thresholds, as well as the values bounding the different susceptibility and vulnerability classes, have to be defined case by case, based on the distribution of the obtained values. At this aim, the following criteria are suggested for susceptibility and vulnerability:

- the median of the distribution should be in the $50 \%$ frequency class;
Table 3 Multiplier for the risk index correction in the presence of mitigation, protection or monitoring measures

\begin{tabular}{lll}
\hline Mitigation or protection measures & & $\begin{array}{l}\text { Multiplier } \\
\rho\end{array}$ \\
\hline $\begin{array}{ll}\text { Effectiveness } \\
\text { Unfavourable (worsening the stability) }\end{array}$ & $\begin{array}{l}\text { Maintenance } \\
\text { Missing or poor }\end{array}$ & 1.2 \\
Not present & & 1 \\
$\begin{array}{l}\text { Partly effective } \\
\text { Partly effective }\end{array}$ & Missing or poor & 0.83 \\
$\begin{array}{l}\text { Favourable (well positioned and } \\
\text { designed) }\end{array}$ & Good & 0.66 \\
$\begin{array}{l}\text { Favourable (well positioned and } \\
\text { designed) }\end{array}$ & Missing or poor & 0.5 \\
\hline
\end{tabular}

- the three classes identified as "high", "moderate" and the sum of "low" and "very low" should have the same amplitude;

- the two extreme classes ("very high" and "very low") should have a frequency equal to $5 \%$.

Instead, the bounding values of the risk index should be defined by the sum of the bounding values of susceptibility and vulnerability, and they should be kept equal for both the initial and residual risk.

\section{The study area}

The study area is located in the Prealpine zone of northern Italy and more specifically in the Lombardy region. The railway infrastructure $19.780 \mathrm{~km}$ long and it develops with a SE-NW direction connecting the Varese Casbeno station (on the Varese Lake, pk 53+375) to the Laveno station (on the Maggiore Lake, pk $72+152$ ), with an altitude ranging from 374 to 199 m a.s.l. (Fig. 3).

In the test area, the railway route spans over 10 municipalities and it passes through 7 stations (in addition to the departing and arriving ones); the infrastructure is mainly single rail, with rail switches and two or three platforms only nearby the stations. The railway route is straight for more
Fig. 2 Iterative scheme for risk assessment, through test on the different thresholds of risk acceptability

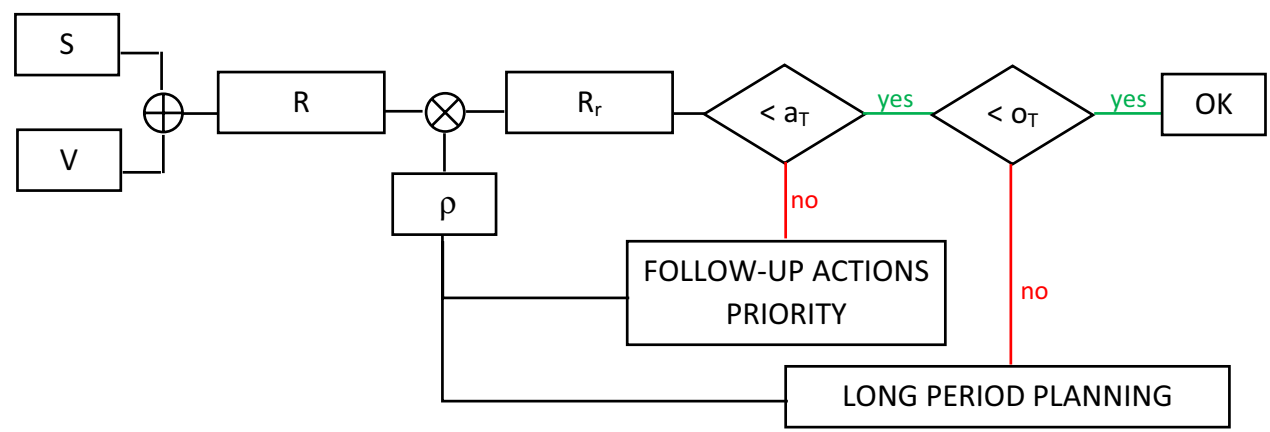




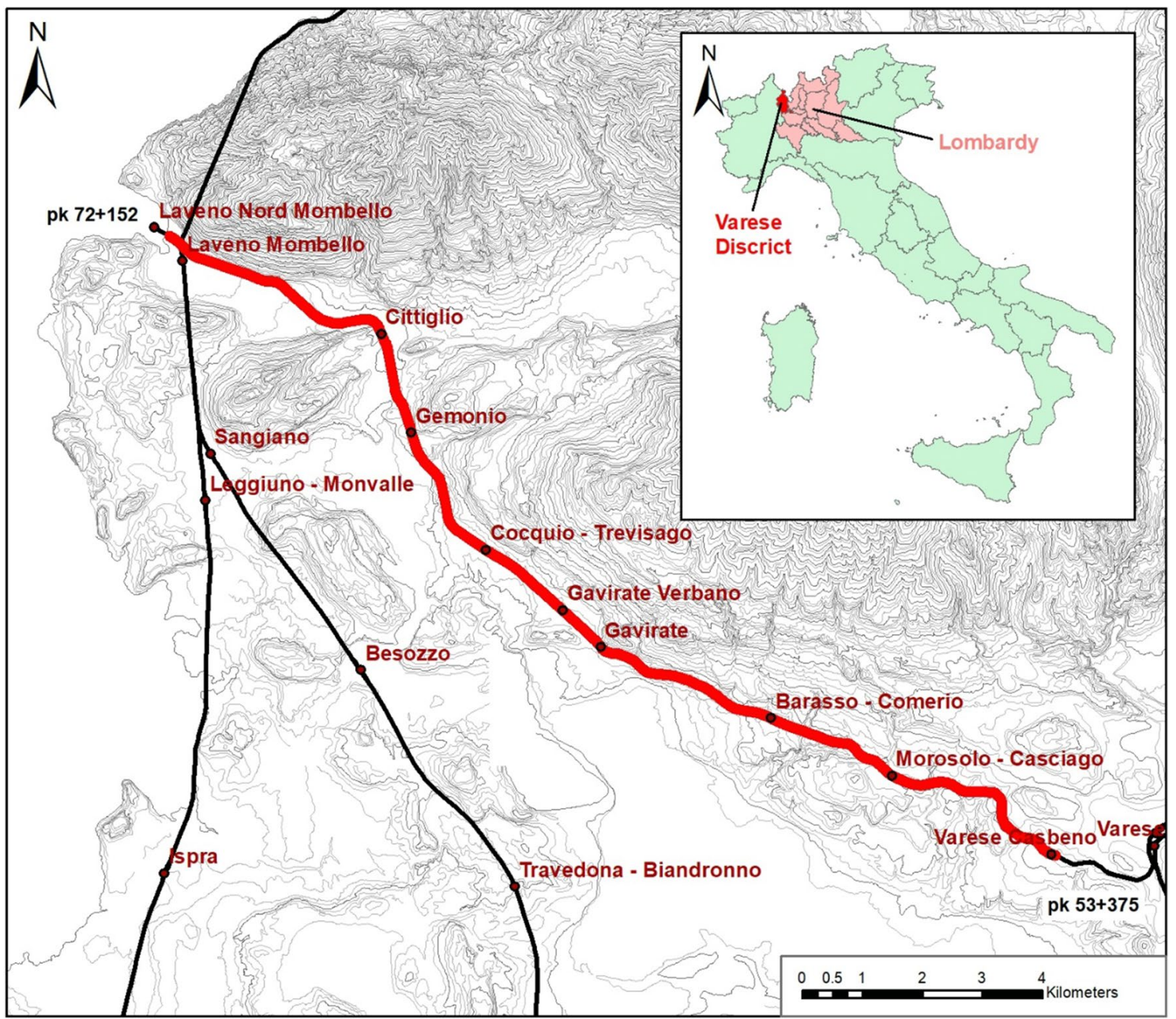

Fig. 3 Location map of the railway infrastructure. In black the whole railway network is shown, whereas in red the studied route is highlighted (based on the DTM of the Lombardy Region http://www.geoportale.regione.lombardia.it)

than its half, with about $20 \%$ in trench and $20 \%$ in embankment. Moreover, 32 bridges and 19 water pipes are present. 39 trains run this route in a day (from 5:30 am to $11: 00 \mathrm{pm}$ ), corresponding to an average frequency of $2.15 \mathrm{train} / \mathrm{h}$. The type of train is always the same and the route speed is $70 \mathrm{~km} / \mathrm{h}$, corresponding to a quite low transit frequency.

From a geological point of view, the study area belongs to the Subalpine structural domain of Southern Alps [20], which is characterised by south-trending overthrusts and folds. It is mainly constituted by Triassic carbonate rocks (mainly dolomites and limestones, with marl intercalations) having a dip direction towards the South with a dip ranging in between $20^{\circ}$ and $40^{\circ}$. The bedrock is locally covered by quaternary deposits, having glacial, fluvioglacial or alluvial origin. These deposits are mainly constituted by sands and gravels in silty or clayey matrix [21]. Moraine hills are mainly W-NW $\div$ E-SE trending. From pk $52+376$ and pk $61+105$ the infrastructure develops along the southern slope of the Campo dei Fiori Massif, which is a carbonate massif characterised by an important karsts aquifer which supplies many springs.

From a hydrological point of view, the infrastructure crosses many rivers. They have mainly a N-S direction, and they are often responsible for local erosive phenomena, bringing about the bedrock outcropping, as well as slope instabilities.

\section{Data collection and on-site surveys}

The available topographic, geological and geomorphological data were collected from several public agencies; then, these data were made homogeneous in order to create a proper database for the following risk analysis.

At this aim, the photogrammetric data of the infrastructure were overlaid on the topographic database (scale 1:1000) in a $500 \mathrm{~m}$ wide strip. Afterwards, the geological 
map (scale 1:5000) was also overlaid, as well as data about geomorphological processes. These latter arise from studies previously carried out for land planning at the municipality scale (1:5000), as well as for the hydraulic risk management at the basin scale $(1: 10,000)$.

In addition to these data, detailed on-site surveys were carried out along the railway infrastructure. Field data were initially collected on Sects. $5 \mathrm{~m}$ long; afterwards, in order to optimise the size of the database with respect to its ability in describing the system heterogeneity, data were aggregated on homogeneous stretches, obtaining sections having a length ranging from 25 to $35 \mathrm{~m}$, for a total number of 486 sections. For each section, a form was filled (Fig. 4), containing parameters related to both the infrastructure (i.e. wideness, type and shape, train speed, etc.) and the geological (i.e. lithology, rock orientation and strength, joint spacing, etc.), geomorphological (i.e. slope angle and height, slope distance, etc.) and hydrogeological (i.e. the presence of water with the corresponding characteristics) data, as well as information on previous instability phenomena (i.e. landslides, rock falls, erosive phenomena, etc.) and existing protection measures (i.e. nets, walls, draining devices, etc., with their conditions). Geometrical information (such as infrastructure wideness or slope height) was simply measured during the on-site surveys; other parameters are qualitative (such as the shape or kind of track, as well as the presence and type of water or vegetation) and they were recorded on the schedule by selecting the proper item in the form (see Fig. 4 for reference). Finally, the geological information was collected by means of traditional geological-technical surveys [22]; more specifically geo-structural and geomechanical surveys were carried out on rock slopes [23], whereas in soil deposits grain size analyses [13] were carried out in order to characterise the soil composition.

Data arising from the on-site surveys populated a georeferenced database, useful for the following risk analysis and management.

\section{Results}

\section{Database}

Based on the data arising from the on-site surveys, the infrastructure mainly develops on soils (less than $2 \mathrm{~km}$ of the route develops on rock masses, corresponding to about the $10 \%$ of the total), and specifically on sands with pebbles (less than $1 \mathrm{~km}$ of the route develops on silty sands). Slopes have an average height of few metres (Fig. 5a), with very different dip angles (Fig. 5b): lower than $20^{\circ}$ for natural and soil slopes and higher than $60^{\circ}$ for rock slopes or slopes with engineering works, such as bridges or retain walls.
As far as previous instabilities, an active landslide affects the infrastructure, involving relevant protection measures. In addition, several rock falls (mainly on the right track) and embankment failures (mainly on the left track) were identified during the on-site surveys, as well as many troubles involving the vegetation cover (Fig. 5c). Water was locally detected, mainly as an outcropping of groundwater (Fig. 5d). In order to face previous instabilities, some protection systems are still present along the infrastructure, such as walls, rockfall nets and draining systems (Fig. 6a), which are generally characterised by a quite good effectiveness (Fig. 6b).

The database contains all the parameters listed in Table 1, divided for track right and left, and it was used for evaluating all the indexes $x_{i}$ and the related scores $y\left(x_{i}\right)$. Many of them (i.e. mapped hazards, vegetation cover, etc.) have a typical stepped behaviour, as they are based on qualitative classes (Fig. 7a). On the contrary, for quantitative parameters, such as slope height and angle, the trend is continuous (Fig. 7b).

\section{Susceptibility, vulnerability and risk}

Based on the score of the different indexes, the landslide hydrogeological susceptibility (S) and the infrastructure vulnerability $(\mathrm{V})$ were assessed along the route of the case study, as well as the initial and residual risk (respectively, $R$ and $R_{r}$ ). The frequency distribution (Fig. 8) is very asymmetric for susceptibility, whereas for vulnerability and risk it assumes a quite typical bell shape, showing higher values for the left track.

In order to divide the railway infrastructure into sections having different risk level, the values bounding the different classes have been defined with reference to the present case study (Table 4), according to the rules listed in Sect. 2.1.

Figure 9 shows the distribution along the railway infrastructure of the different classes of susceptibility, vulnerability and risk. Results point out that:

- in the NW sector there are some sections with high susceptibility, mainly arising from fluvial dynamics and active landslides affecting the slope; the presence of high slope angle and water locally increases the susceptibility. The vulnerability is quite high, too, because of the short distance between the rail and the edge of slopes, especially along the left track. As a consequence, the risk index is from moderate to high for long distances, even if the presence of mitigation measures locally reduces the residual risk;

- in the central sector the sections having high susceptibility correspond to zones characterised by silty loose soils with water or rock slopes affected by block fall. The vulnerability is also high, bringing about high values of the risk index, especially along the left track. The presence of mitigation measures partly reduces the residual risk; 


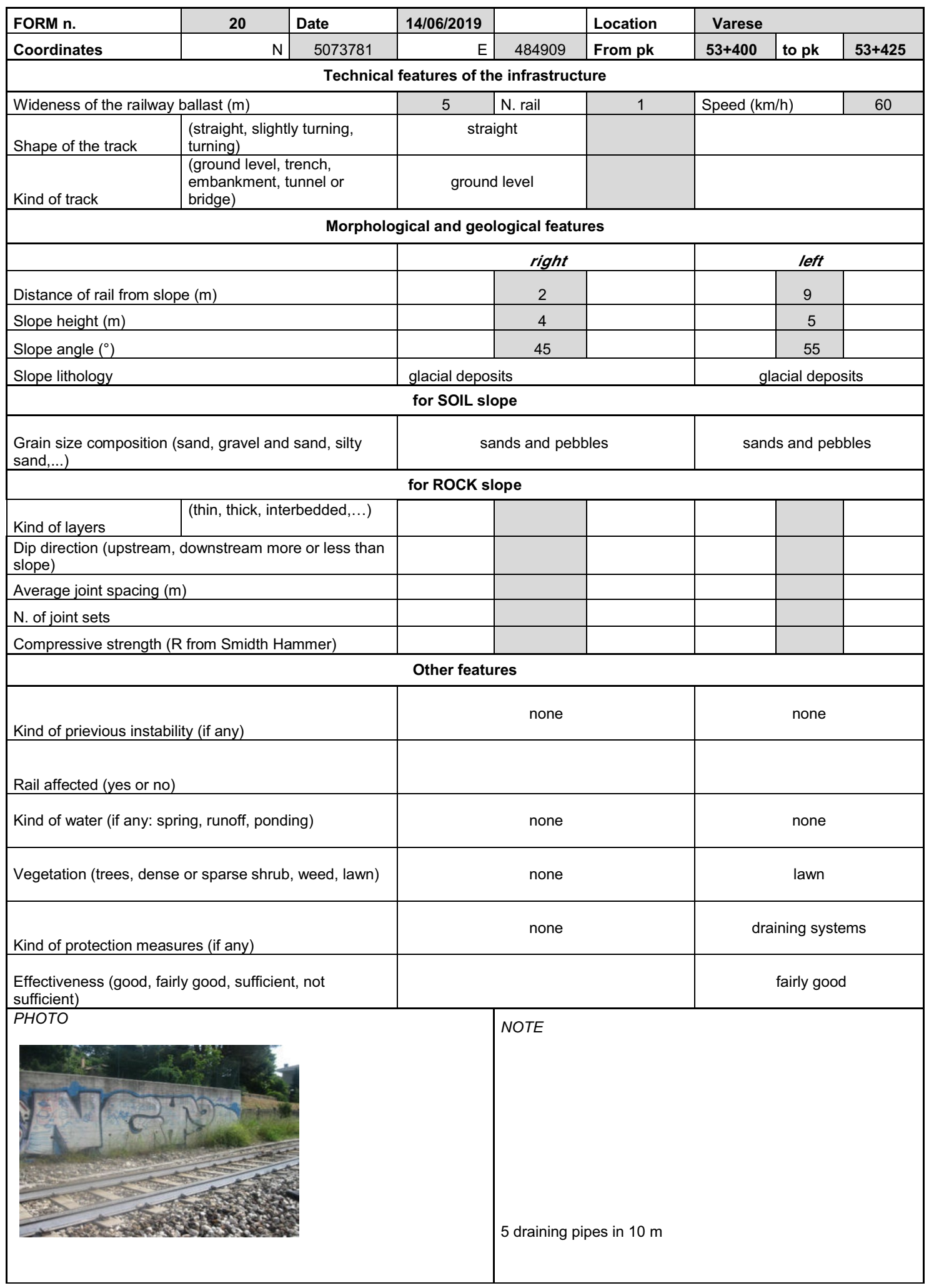

Fig. 4 Example of the schedule filled during the on-site survey in order to collect data for the RHMS application 
(a)

Slope hieght $(\mathrm{m})$ distribution

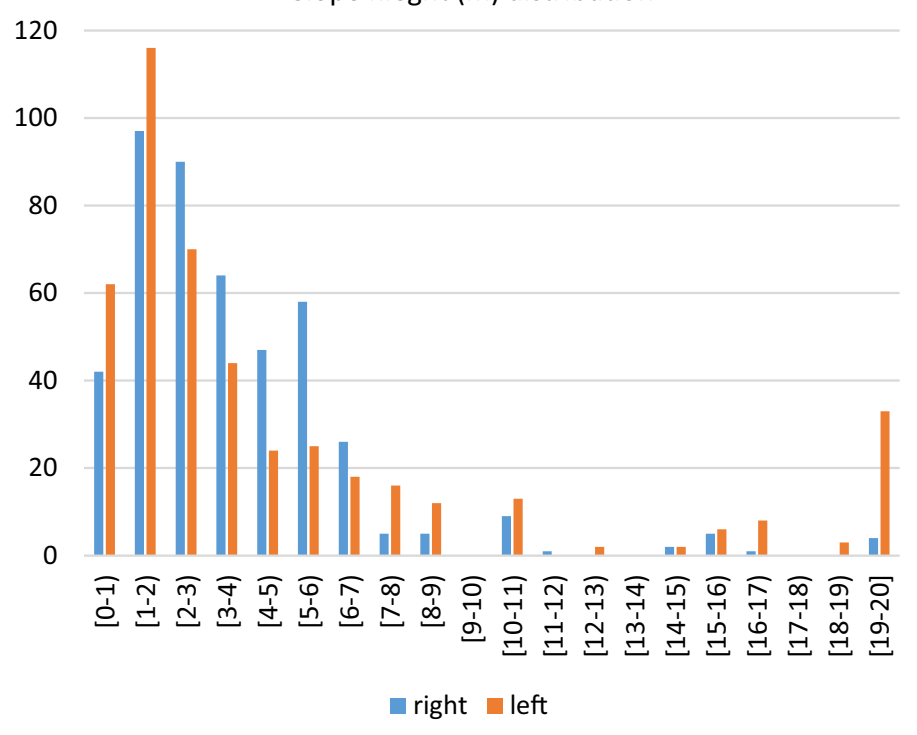

(b)

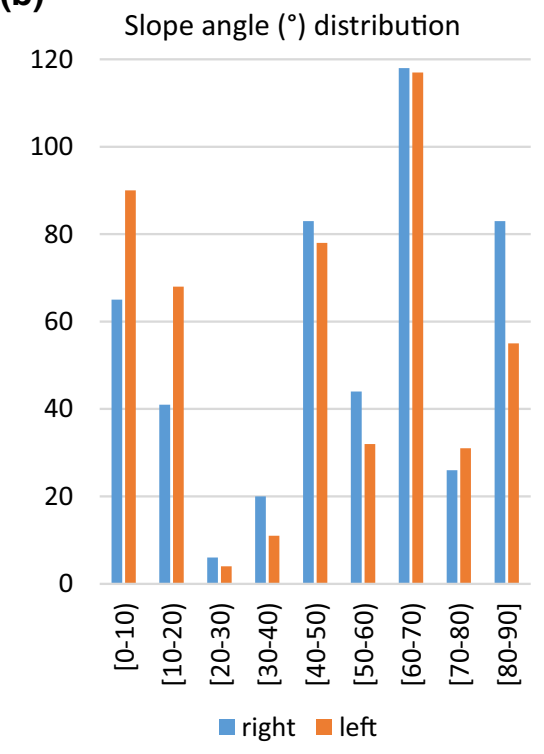

(c)

Kind of instability

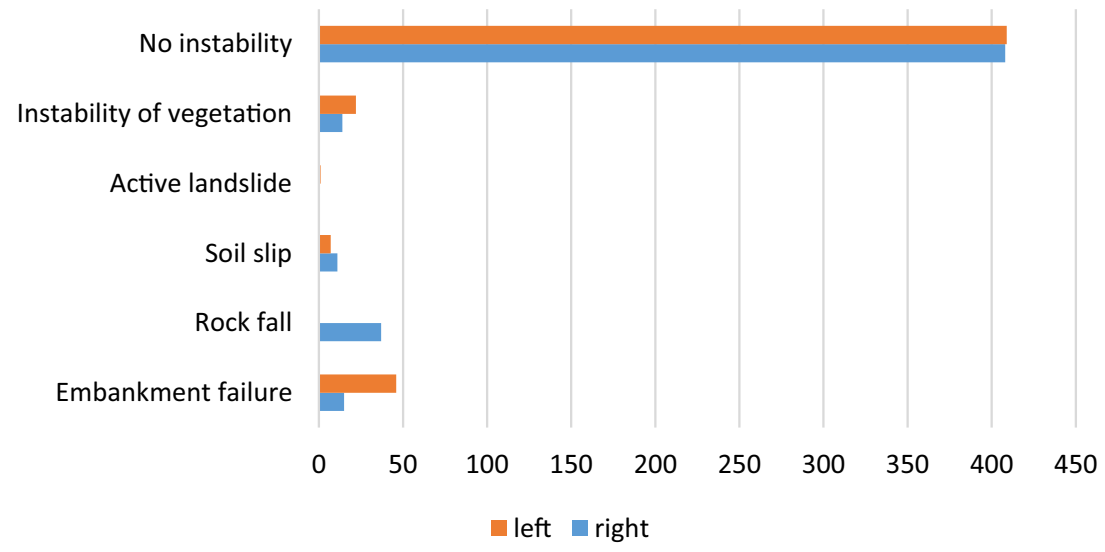

(d)

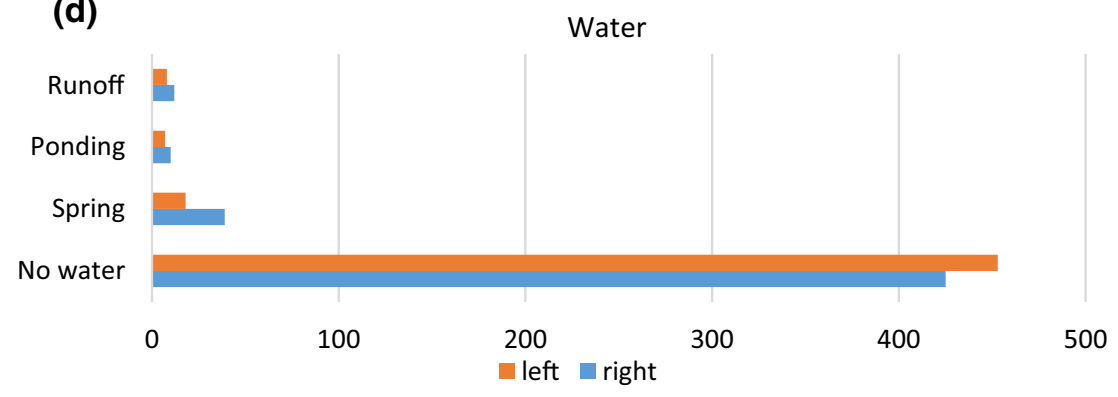

Fig. 5 Example of data stored in the database: class distribution of a slope height, $\mathbf{b}$ slope angle, $\mathbf{c}$ previous instability, and $\mathbf{d}$ water. The number refers to the sections (the total number of sections is equal to 486 for each direction, right and left) for which the survey was carried out

- in the SE sector there are no relevant hydrogeological problems; the susceptibility is high only on very short distances (i.e. where the slope angles are higher). The vulnerability is quite low; therefore, the risk is generally low, too. 
Fig. 6 Existing protection measures along the railway infrastructure (a), with their effectiveness (b)

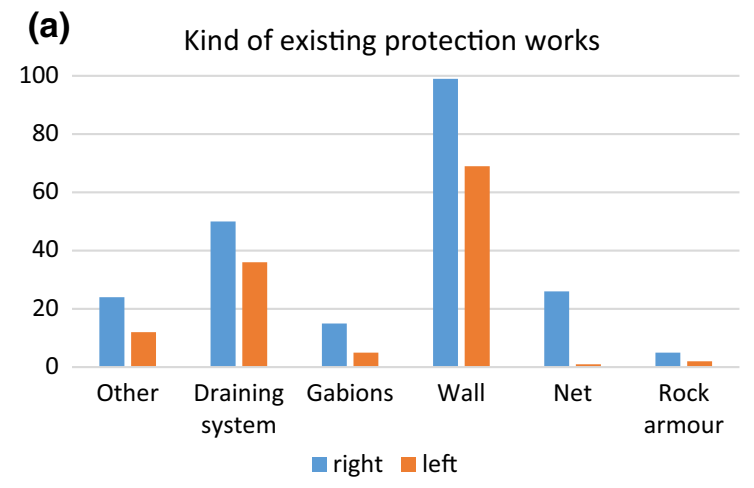

(b) Effectivennes of protection works

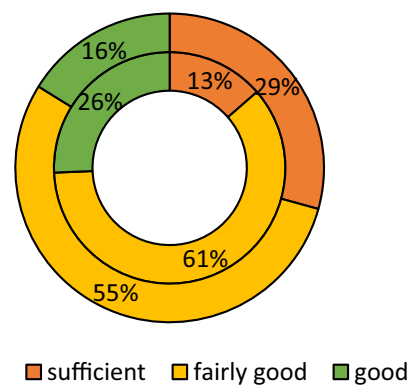

Fig. 7 Examples of the score $\mathrm{y}\left(\mathrm{x}_{\mathrm{i}}\right)$ along the infrastructure for a qualitative parameter (previous instabilities) and $\mathbf{b}$ a quantitative parameter (slope angle)

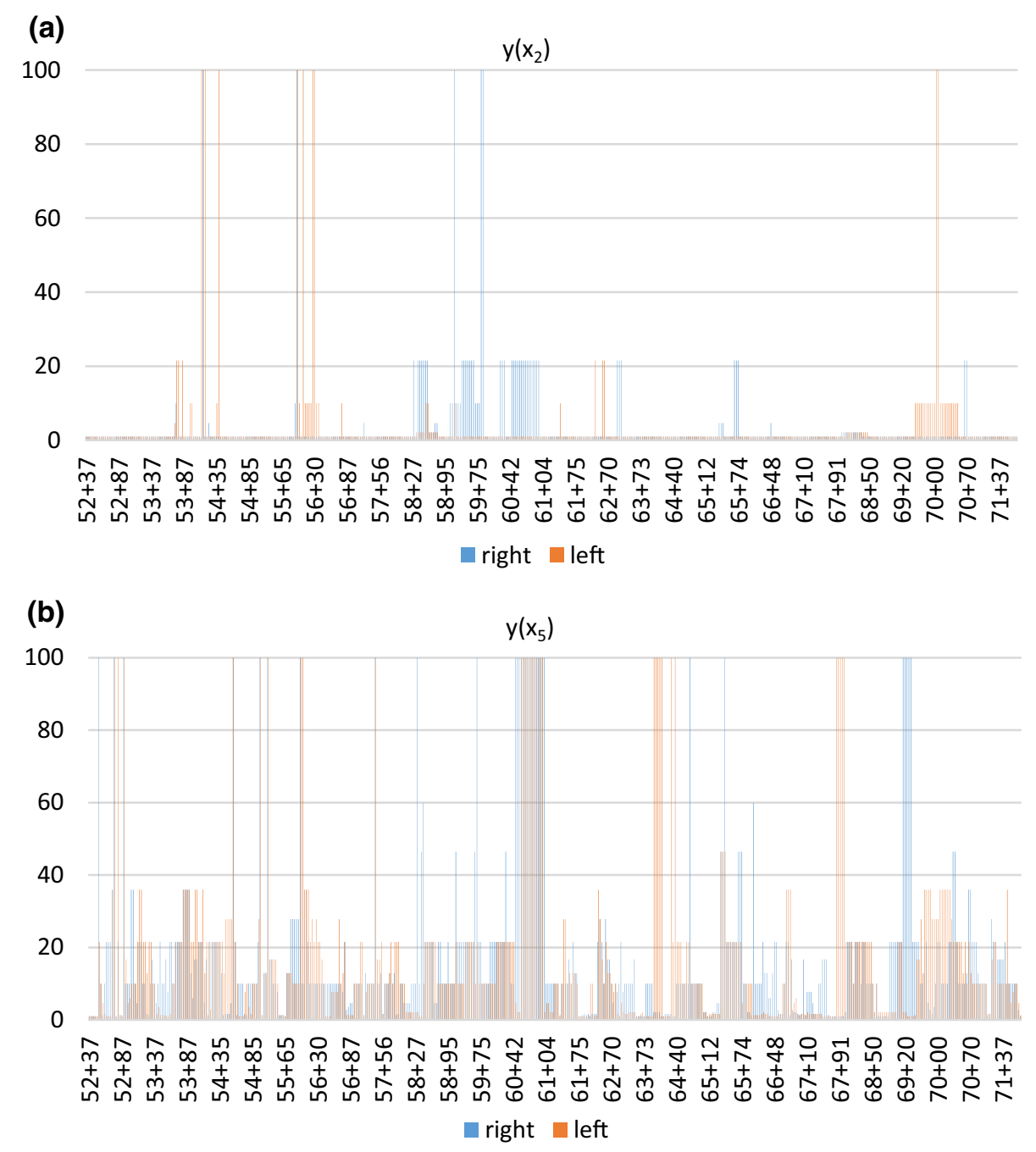

\section{Risk management}

In order to prioritise the follow-up actions along the railway infrastructure, for the case study an acceptability threshold for the risk index equal to 260 was adopted, which means that "high" and "very high" classes are not acceptable. In order to exclude very local situations, "high" risk values were considered only if the two adjoining sections had values higher than 195 (corresponding to the intermediate value of the "moderate" class). 

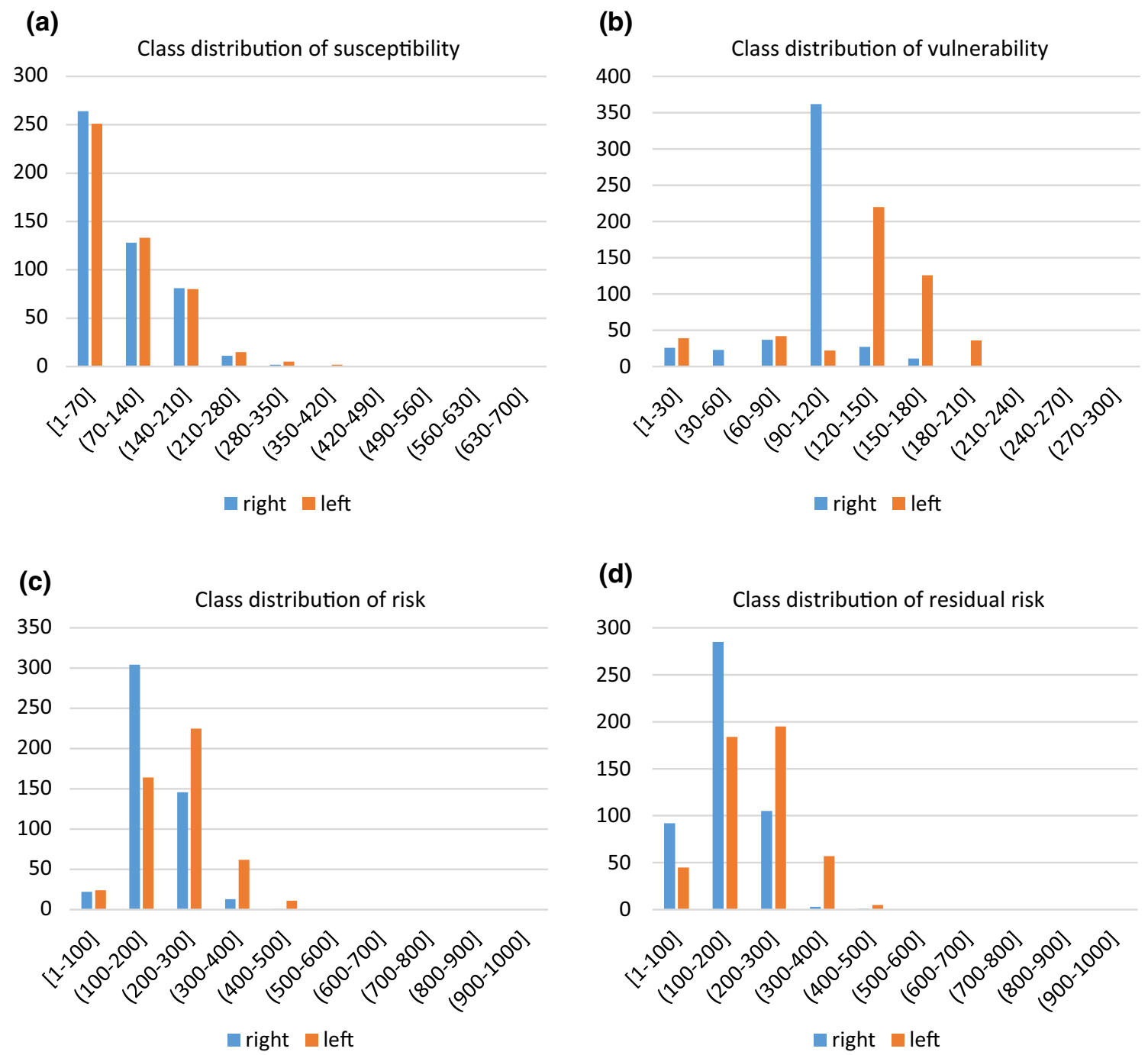

Fig. 8 Frequency distribution of the values of susceptibility (a), vulnerability (b), risk (c) and residual risk (d) for the 486 sections of the railway infrastructure

In this way, for the case study the intervention priorities with the corresponding protection or mitigation measures were identified (Table 5).

The risk assessment should be updated yearly or after the realisation of new protection and mitigation works, in order to reach an acceptable level of risk along the whole

Table 4 Classes of landslide hydrogeological susceptibility (S), infrastructure vulnerability (V) and risk (R) for the case study

\begin{tabular}{llll}
\hline & Susceptibility & Vulnerability & Risk \\
\hline Very high & $\mathrm{S}>210$ & $\mathrm{~V}>180$ & $\mathrm{R}>390$ \\
High & $140<\mathrm{S} \leq 210$ & $120<\mathrm{V} \leq 180$ & $260<\mathrm{R} \leq 390$ \\
Moderate & $70<\mathrm{S} \leq 140$ & $60<\mathrm{V} \leq 120$ & $130<\mathrm{R} \leq 260$ \\
Low & $21<\mathrm{S} \leq 70$ & $9<\mathrm{V} \leq 60$ & $30<\mathrm{R} \leq 130$ \\
Very low & $\mathrm{S} \leq 21$ & $\mathrm{~V} \leq 9$ & $\mathrm{R} \leq 30$ \\
\hline
\end{tabular}

infrastructure. Eventually, based on socio-economic issues, a target threshold can be defined in addition to the acceptability one: it will be the value to which aim in the long term.

\section{Discussion}

The proposed heuristic method provides a useful tool for hydrogeological risk management along railway, as it allows to compare the relative values of hazard, vulnerability and risk in the different sections of an infrastructure; therefore, it gives a priority scale for the follow-up actions.

Based on the application to the case study, the method constitutes a good compromise between the desire to fully describe the complexity of the phenomena and the need to 


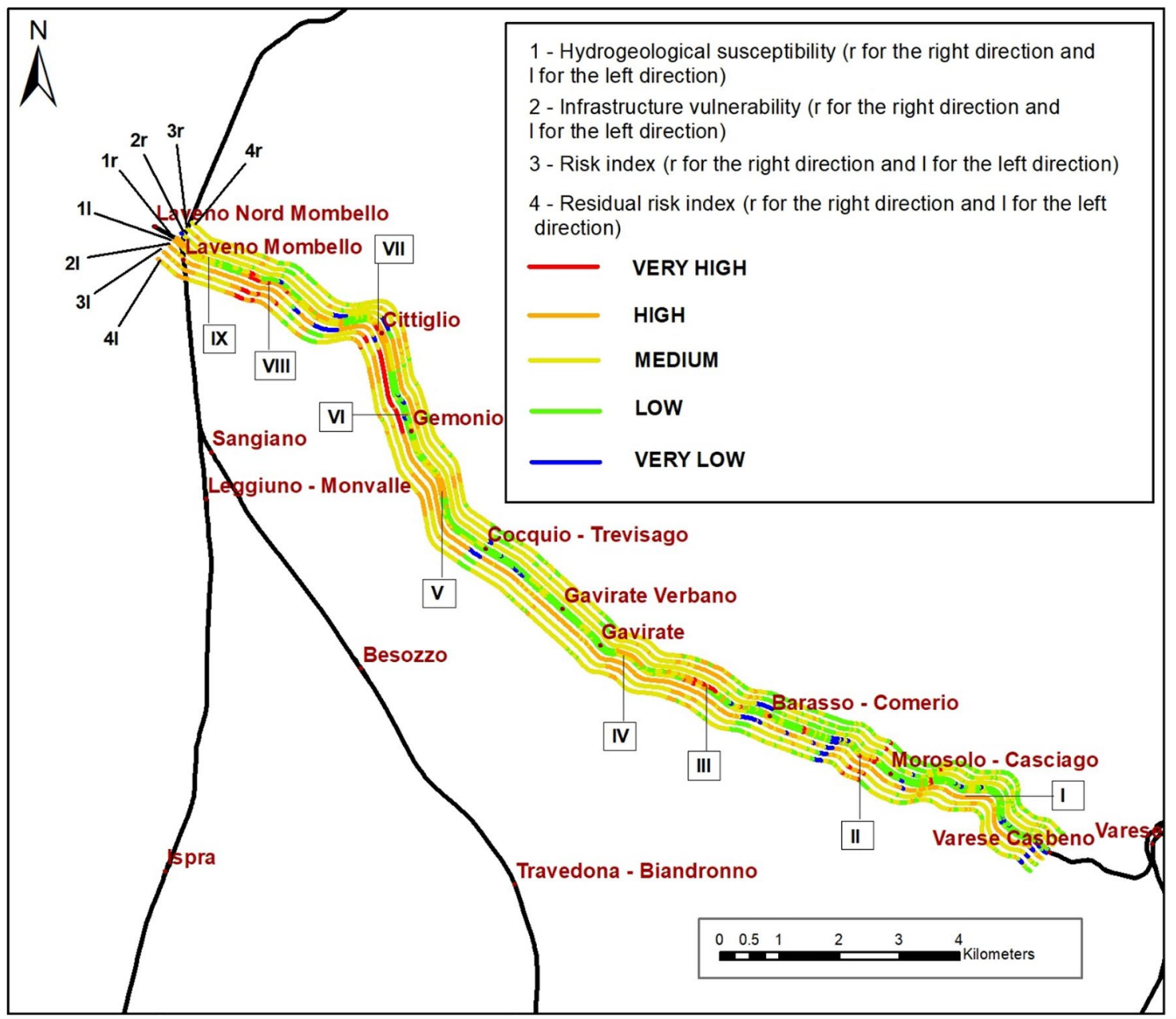

Fig. 9 Susceptibility, vulnerability, risk and residual risk for the case study, based on the ranking defined in Table 4. The Roman numbers show the location of the priority actions listed in Table 5

Table 5 Follow-up priority actions for the case study and the corresponding protection/mitigation measures

\begin{tabular}{lll}
\hline ID & Problem & Measure \\
\hline I & High slope angle with embankment failure and weed vegetation & Structural measures along the slope and vegetation removal \\
II & Erosive phenomena & Maintenance and reinforcing works \\
III & Active landslide (left track) & Structural protection measures \\
IV & Rock subvertical slopes with block fall (right track) & Structural protection and draining measures \\
V & Loose soils in the presence of water and high slope angle & Monitoring of the existing draining system effectiveness \\
VI & Water run-off & Realisation of draining systems \\
VII & High hydraulic hazard (fluvial dynamics) & Vegetation removal and monitoring of the existing draining \\
& & system effectiveness \\
VIII & Embankment failure (left track) & Structural protection measures \\
IX & Active landslide on the slope above the infrastructure & Monitoring system for block impact along the tracks \\
\hline
\end{tabular}

Their location is shown in Fig. 9

simplify the problem in order to supply a tool easy to apply and update, even by unskilled users.
Actually, the data can be collected and updated with onsite surveys in time intervals compatible with the functional needs of the infrastructure, with no service interruptions. 
For example, even if the geological conditions described by the corresponding parameters (see Table 1 for reference) is not complete, the application to the case study demonstrated that a reliable identification of the geological critical issues in rock masses can still be achieved. Moreover, the exponential ranking system used in the present study demonstrated to be able to emphasise the most critical situations.

One of the main differences of the proposed method with respect to other methods usually applied for geological hazard assessment along highways is related to the braking distance. Braking distance expresses the possibility that a driver can stop his vehicle before impacting an obstacle. The value of this parameter is usually obtained as the ratio between the actual view and the braking distance of the vehicle. For a train that run at a speed of $70 \mathrm{~km} / \mathrm{h}$ the braking distance is at least $500 \mathrm{~m}$ and therefore well above the driver's actual view. For this reason, in the present study a different parameter was considered as representative of the possibility of reporting any problems along the infrastructure; at this aim the distance from the signalling systems was taken into account (see Sect. 2.1 for the definition of the parameter). This parameter is relevant only whether a monitoring and early warning system is present along the route. One of the few examples of real-time monitoring for geological risk management along railway concerns rock falls detection in central Italy, where a prototype of artificial intelligence camera is used [24]. Unfortunately, no monitoring system is still present in the case study; therefore, this parameter could not be considered in the method application and its weight was equally distributed to the other two parameters describing the vulnerability.

\section{Conclusions}

Although railway infrastructures in mountain areas are often affected by relevant geological and hydrogeological hazards, in the technical international literature this topic is overlooked and therefore it is necessary to refer to methods already developed for the risk assessment along highways.

The present study aims at filling this gap, by pointing out a heuristic method for hydrogeological risk assessment and management along railway infrastructures, with specific reference to geomorphological conditions typical of the Prealpine zone (northern Italy). The proposed method allows:

- to assess the hydrogeological susceptibility, vulnerability, risk and residual risk along any railway infrastructure having geomorphological features typical of mountain areas;

- to identify a priority scale in the follow-up measures, based on the definition of acceptability thresholds specific for each case study.
One of the main advantages of the proposed method is its ability to combine a reasonable degree of complexity in describing the problem with a user-friendly approach, which is not much time consuming in data collection and processing. Moreover, the method can be applied with an iterative approach, updating the evaluation and eventually the thresholds, depending on the evolution of the political and socio-economic conditions.

The main disadvantage of the proposed method is the relative scale in which the results are expressed. Actually, the obtained results cannot be looked as an absolute risk rating, as the method is based on a heuristic approach. As a consequence, the resulting risk rating has a relative validity, which only allows to identify some sections as more critical than other ones.

Acknowledgments The study belongs to a collaboration between Politecnico di Milano and FerrovieNord S.p.a. and more specifically to the following research deal "Definizione di una metodologia di valutazione del pericolo da frana lungo le infrastrutture di FerrovieNord", funded by FerrovieNord S.p.a.

Funding Open access funding provided by Politecnico di Milano within the CRUI-CARE Agreement.

\section{Compliance with ethical standards}

Conflict of interest The authors declare no conflict of interest.

Open Access This article is licensed under a Creative Commons Attribution 4.0 International License, which permits use, sharing, adaptation, distribution and reproduction in any medium or format, as long as you give appropriate credit to the original author(s) and the source, provide a link to the Creative Commons licence, and indicate if changes were made. The images or other third party material in this article are included in the article's Creative Commons licence, unless indicated otherwise in a credit line to the material. If material is not included in the article's Creative Commons licence and your intended use is not permitted by statutory regulation or exceeds the permitted use, you will need to obtain permission directly from the copyright holder. To view a copy of this licence, visit http://creativecommons.org/licenses/by/4.0/.

\section{References}

1. Carretero J, Pérez JM, Garcia-Carballeira F, Calderon A, Fernandez J, Garcia JD, Lozano A, Cardona L, Cotaina N, Prete P (2003) Applying RCM in large scale systems: a case study with railway networks. Reliab Eng System Safety 82:257-273

2. Varnes DJ (1984) The principles and practices of landslide hazard zonation. UNESCO Press, Paris

3. An M, Chen Y, Baker CJ (2011) A fuzzy reasoning and fuzzyanalytical hierarchy process based approach to the process of railway risk information: a railway risk management system. Inf Sci 181(18):3946-3966

4. Pellicani R, Spilotro G, Van Westen CJ (2016) Rockfall trajectory modelling combined with heuristic analysis assessing the rockfall hazard along the Maratea SS18 costal road (Basilicata, southern Italy). Landslides 13(5):985-1003 
5. Pantelidis L (2011) A critical review of highway slope instability risk assessment systems. Bull Eng Geol Environ 70:395-400

6. Scesi L, Seno S, Gioia U, Mazzucchelli A (2001) Pareti rocciose instabili e strade: un sistema di valutazione delle priorità di intervento (Instable rock slopes and roads: a system for identify the intervention priorities). GEAM 102:75-82

7. Pierson LA, Van Vikle R (1993) Rockfall hazard rating system (RHRS). Transport Department of Oregon, USA

8. Gioia U, Scesi L (1999) Approccio integrato all'instabilità dei versanti stradali (Integral approach to slope stability along roads). Le Strade, 1347, 102-107. ISSN:0373-2916

9. Ko C, Chowdhury R, Flentje P (2005) Hazard and risk assessment of rainfall: induced landsliding along a railway line. Quart J Eng Geol Hydrogeol 38(2):197-213

10. Bieniawski ZT (1989) Engineering Rock Mass Classifications. Wiley, New York

11. Romana M (1991) SMR classification. In: Proceedings of 7th international congress on rock mechanics, vol 2, pp 955-960.

12. Budetta $P$ (2004) Assessment of rockfall risk along roads. Nat Haz Earth Syst Sci 4:71-81

13. Active Standard ASTM D422-63 (2007) Standard test methods for particle-size analysis of soils.

14. Gattinoni P (2009) Parametrical landslide modeling for the hydrogeological susceptibility assessment: from the Crati Valley to the Cavallerizzo landslide (Southern Italy). Natl Hazard 50:161-178

15. Gattinoni P, Francani V (2009) A tool for modeling slope instability triggered by piping. World Acad Sci Eng Technol 56.
16. Sati SP, Sundriyal YP (2007) Role of some tree species in slope instability. Himal Geol 28(1):75-78

17. Stokes A, Norris JE, van Beek LPH, Bogaard T, Cammeraat E, Mickovski SB, Jenner A, Di Iorio A, Fourcaud T (2008) How vegetation reinforces soil on slopes. In: Norris JE, et al. (eds) Slope stability and erosion control: ecotechnological solutions. Springer, Dordrecht. Doi:https://doi.org/10.1007/978-1-4020-6676-4_4.

18. Ferlisi S, Cascini L, Corominas J et al (2012) Rockfall risk assessment to persons travelling in vehicles along a road: the case study of the Amalfi coastal road (southern Italy). Nat Hazards 62:691-721

19. Jhong BC, Huang J, Tung CP (2019) Spatial assessment of climate risk for investigating climate adaptation strategies by evaluating spatial-temporal variability of extreme precipitation. Water Resour Manag 33:3377-3400

20. Italian Geological Society (1990) Guide Geologiche Regionali: Alpi e Prealpi Lombarde. Lombardy Alps and Prealps, Regional Geological Guides

21. Bini A (1987) L'apparato glaciale Wurmiano di Como. Università degli Studi di Milano, Tesi di dottorato di ricerca, pp 1-569

22. Bell FG (2007) Engineering geology. Elsevier, p. 592.

23. Hoek E, Bray JW (1974) Rock slope engineering. Instit Min Metal, p. 402.

24. Fantini A, Fiorucci M, Martino S (2017) Rock falls impacting railway tracks: detection analysis through an artificial intelligence camera prototype. Wireless Commun Mobile Comput 1-11. 